\title{
Performance of Various SiC Devices and their Behavior in DC/DC Converter
}

\author{
K. V. R. Swathi, U. Salma.
}

\begin{abstract}
An extensive research on nano materials was carried out and the properties of Si were studied, Post study it was felt that there must be a material which exhibits semiconducting properties of Si with high breakdown voltage and work till high temperature range. Silicon Carbide $(\mathrm{SiC})$ devices provided the answer for this. These devices are well known for high frequency, high voltage, high temperature and high power for their good material properties compared with silicon power MOSFET. In this paper, a study was conducted on various Silicon Carbide devices available in the market and the comparative performance of these devices were analysed. Furthermore there is a comparison of $N$ channel silicon MOSFET device and silicon carbide device placed in bidirectional DC/DC buck converter in which Silicon Carbide device exhibit superior properties than Si device.
\end{abstract}

Keywords : Silicon carbide devices, bi directional dc/dc buck converter, Silicon Mosfet, Power loss

\section{INTRODUCTION}

The gradual progress in use of semiconductors, particularly silicon, brought a change in the technology and contributed massively for the good being of Human race. The continues effortsfor size reduction goverened by moore's requires further research on silicon nanostructures (SiNSs) in different forms. Though $\mathrm{Si}$ dominates the electronics field, the photonic properties of Silicon are considered to be poor because of its indirect band gap. The opto electronic devices show less efficiency in photon absorption and emission which results in restriction of bulk use in comparison to its competitors.

After the properties of $\mathrm{Si}$ were studied, it was realized that there must be a material which exhibits semiconducting properties of Silica with high breakdown voltage and also work in high temperatures. Researchers have undergone many process and found silica carbide. Silica Carbide is a compound of Silicon and carbon, which replaces Silicon for high temperature and high power devices and electrical devices. Because of the combination of such desirable mechanical properties, like hardness, resistance, above all the resistance to corrosion, inertness to chemicals, response to electromagnetic field and compatibility in living organisms and other industries [7]. Furthermore, because of its low coefficient of thermal expansion, high thermal conductivity, low wet ability bymolten metal and low density, Silica Carbide is commonly used for heat resistant parts and refractory applications [8].

Thus nanotechnology in $\mathrm{SiC}$ plays a very crucial role. However, occurrence of SiC naturally is very less.

Revised Manuscript Received on December 13, 2019.

* Correspondence Author

K.V.R.Swathi*, Dept of EEE, Anil Neerukonda Institute of technology and sciences, Visakhapatnam, India. Email: swathi.korukonda22@gmail .com

Dr.U.salma, Dept of EECE, GITAM, Visakhapatnam, India. Email: swathi.korukonda22@gmail.com

Its synthesis it requires high temperature conditions for its synthesis and obtaining pure $\mathrm{SiC}$ which is a very cumbersome process. One Such technique is Thermal plasma assisted technique which is a high temperature process and can be used for synthesis of Silica Carbide nano particles (SiCNPs). On the whole , the plasma processes [10], is best tool for fabricating different kinds of nano particles, films and coatings.

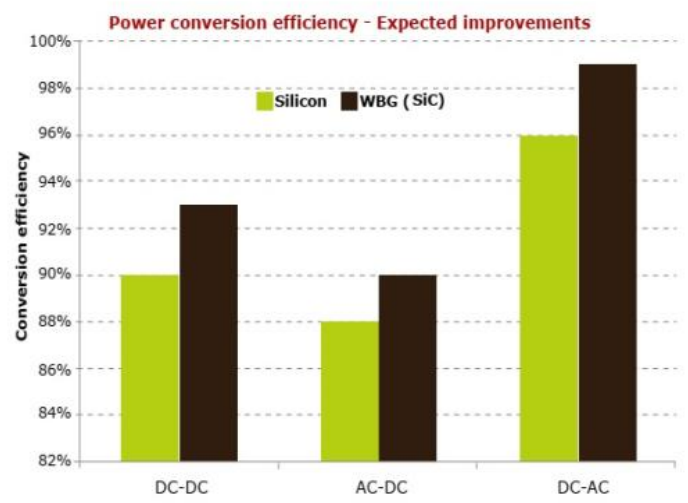

Fig 1: Improvement in power conversion efficiency of $\mathrm{SiC}$

When compared to $\mathrm{Si}$ semiconductors, $\mathrm{SiC}$ is a semiconductor with wide energy bandgap and interesting properties . The properties of Silica Carbide and Silicon are presented in Table 1. The bandgap energy of Silica Carbide is wide that leads to lower current leakage in blocking mode and a higher junction temperature [7]. The bandgap of energy of Silica Carbide, which is three times wider than the Silicon bandgap of energy, which means it takes a more energy for electrons to free from their respective valence bands.

Table: 1 Properties of $\mathrm{Si}$ and $\mathrm{SiC}$

\begin{tabular}{|l|c|c|}
\hline Properties & Si & SiC \\
\hline Bandgap of Energy [electronVolt] & 1.13 & 3.16 \\
\hline Electric breakdown field [Volt/cm] & 212 & 2120 \\
\hline Mobility of Electron $[\mathrm{cm} 2 / \mathrm{Vs}]$ & 1401 & 1001 \\
\hline Thermal conductivity $\left[\mathrm{Watt} / \mathrm{cm}^{\circ} \mathrm{C}\right]$ & 1.4 & 3.6 \\
\hline Dielectric constant & 11.6 & 9.6 \\
\hline Drift velocity of Saturated electron $[\mathrm{cm} / \mathrm{sec}]$ & 106 & 212 \\
\hline
\end{tabular}

\section{POWER CALCULATION ANALYSIS OF SIC DEVICES:}

Designers get attracted to the desirable features of the $\mathrm{SiC}$ device which are low leakage currents at high operating temperatures; high breakdown field strength, high electron saturation velocity, which results in faster turn-on and turn-off process; high thermal conductivity and high power densities. The most important aspect for considering performance evaluation in designing of a power electronic system is POWER LOSS.

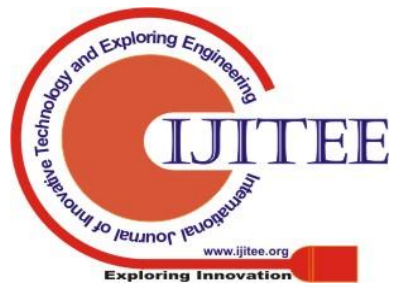


For power loss calculation using $\mathrm{SiC}$ devices the main parameters that effect is the on state resistance of the device, parasitic capacitance, gate voltage are considered.

\section{A. On Resistance $\mathbf{R}_{\mathrm{ds}(\mathbf{o n})}$ :}

The) is effected by gate drive voltage they are inversely propotional to each other and a considered limit is established to avoid voltage breakdown. The behaviour On Resistance of depends on the drift layer resistance, channel resistance and temperature. The channel resistance is temperature when there inversely propotional to temperature. Later the drift layer resistance, increases with the increase in temperature as there is an increase in lattice vibration that is scattering of the electrons.

\section{B. Device Capacitance:}

A SiC mosfet consists of three parasitic capacitors which are placed in between gate, drain, and source. The input capacitance is given as the sum of gate drain capacitance and gate source capacitance. The output capacitance is the sum of drain source capacitance and gate drain capacitance and the reverse transfer capacitance is equal to gate drain capacitance. For low threshold voltage the on-resistance decreases when temperature is high. The gate driver circuit should be designed carefully to avoid false triggering.

\section{Higher operating temperature:}

Silicon carbide devices have a high melting temperature. Silicon carbide devices operate at high temperature of about $400^{\circ} \mathrm{C}$ while $\mathrm{Si}$ technology operates at $150^{\circ} \mathrm{C}$. This property results in cost reduction and cooling of the system. Considering high ambient air temperature, around $100^{\circ} \mathrm{C}$ the temperature differential can be obtained when the heat is out of the semiconductor package.

\section{Power loss Analysis of SiC Devices:}

For calculating the conduction losses of the silicon carbide devices we need to analyze the static characteristics of the device. These characteristics are obtained from data sheets of the devices and are strongly dependent on the temperature effect. Hence the design of heat sink is carefully observed to improve the device performance.

The silicon diodes have a negative temperature coefficient while Silicon Carbide diodes have positive temperature coefficient.

For calculating the switching losses of the silicon carbide devices we need to analyze the dynamic characteristics of the device. The procedure for turn off method is similar for silicon diodes and silicon carbide diodes hence the waveforms in off state are also similar.

The losses in a switch consist of conduction loss and switching loss. The parameter is named as $\mathrm{P}_{\text {losses }}$ is the total losses in a switch, $\mathrm{P}_{\text {cond }}$ conduction losses, $\mathrm{P}_{\mathrm{sw}}$ switching losses. $\mathrm{R}_{\mathrm{ds}(\mathrm{on})}$ on resistance, $\mathrm{I}_{\text {load }}$ load current, $\mathrm{V}_{\mathrm{dc}}$ drain source voltage, $\mathrm{E}_{\text {ton }}$ turn on energy, $\mathrm{E}_{\text {toff }}$ turn off energy, $\operatorname{Cos} \Phi$ power factor, $\mathrm{V}_{\text {ref }}$ reference voltage, $\mathrm{I}_{\text {ref }}$ reference current. The Electrical properties of $\mathrm{SiC}$ devices with $\mathrm{Si}$ based Mosfet is shown in table 1:

Conduction Loss Analysis:The conduction losses of the Mosfet are directly dependent on its on state resistance and load current. The on state resistance is directly depended on the Mosfet junction temperature.

$\mathrm{P}_{\text {cond }}=\frac{1}{2} \frac{\mathrm{R}_{\mathrm{ds} O \mathrm{~N}}}{4}\left(\mathrm{I}_{\text {load }}\right)^{2}+\mathrm{mCos} \emptyset \frac{\mathrm{R}_{\mathrm{ds} O \mathrm{~N}}}{3 \pi}\left(\mathrm{I}_{\text {load }}\right)^{2}(1)$

$$
P_{\text {cond }}=R_{\text {dsON }}\left(I_{\text {load }}\right)^{2}\left\{\frac{1}{8}+\frac{m \operatorname{Cos} \emptyset}{3 \pi}\right\}
$$

Switching Loss Analysis: Usually for soft switching low switching losses are obtained but for hard switching mode in turn off state of the switch the current is assumed to linearly decrease to zero and at the turn on state voltage is assumed to linearly decrease to zero. Then the switching losses can be given by

$$
\begin{aligned}
& P_{\text {swit }}=\frac{f_{\text {swit }}}{\pi}\left[E_{T, \text { on }}+E_{T, \text { off }}\right] \frac{V_{\text {dc }} I_{\text {load }}}{V_{\text {ref }} I_{\text {ref }}}(3) \\
& P_{\text {swit }}=\frac{f_{\text {swit }}}{\pi}\left[E_{T, \text { off }}\right] \frac{V_{\text {dc }} I_{\text {load }}}{V_{\text {ref }} I_{\text {ref }}}(4)
\end{aligned}
$$

The performance characteristics of various silicon carbide devices like Rohm 300A, Rohm 180A, Rohm 120A,Microsemi295A, Microsemi250A,Cree 404A,Cree 225AandSemikron 541A is obtained based on the power loss calculations and it is observed that these devices shows better performance than IGBT 400A.

The Cree 4040A is best suitable for robotic applications. Different parametric waveforms are obtained for the proposed high gain converter and analyzed. The converter avoids extended duty ratio and voltage stress which helps in reducing the switching losses of active switches improves the efficiency and high voltage gain which is needed for robotic applications.

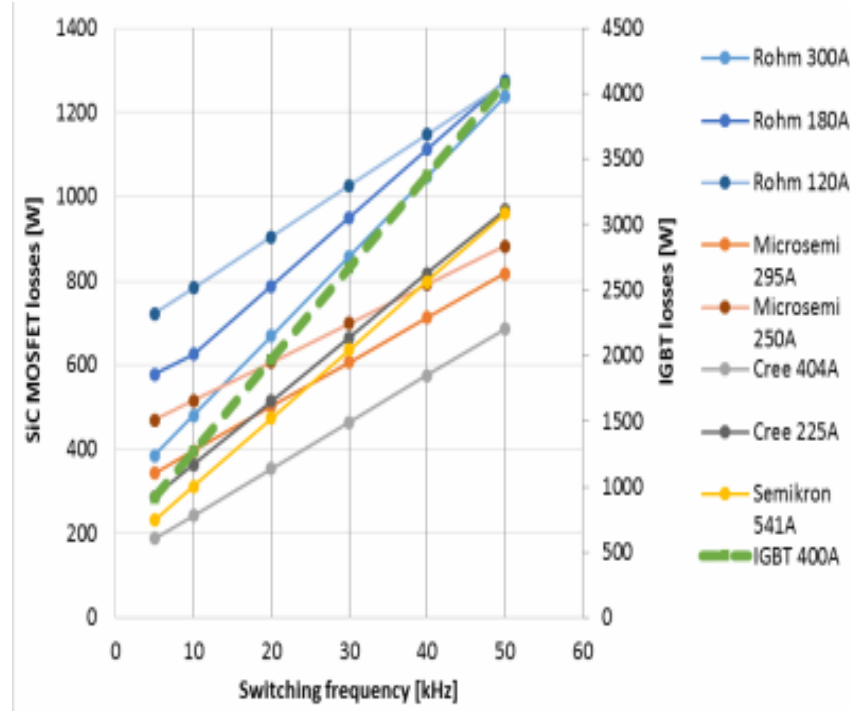

Fig 2: Total losses in SiC MOSFET and IGBT

From Figure 2 the total conduction and switching losses is shown and it is observed that IGBT(400A) Si Device losses from $5 \mathrm{KHz}$ to $50 \mathrm{KHz}$ varies from $1000 \mathrm{~W}$ to $4000 \mathrm{~W}$ while the $\mathrm{SiC}$ device Cree (404A) varies from $200 \mathrm{~W}$ to $700 \mathrm{~W}$ for the same frequency level above results show various $\mathrm{SiC}$ devices losses which are of minimum extent. 


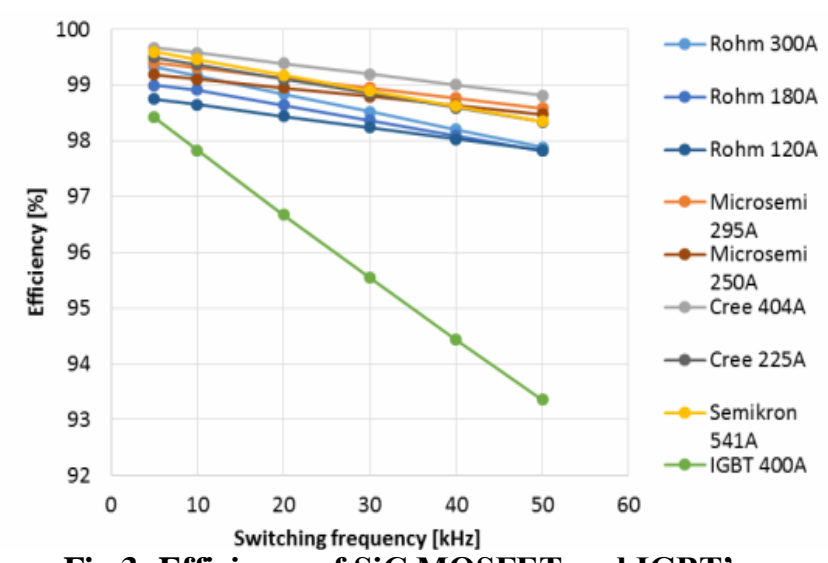

Fig 3: Efficiency of SiC MOSFET and IGBT's

From Figure 3 shows the efficiency characteristics and it is observed that IGBT(400A) Si Device efficiency from $5 \mathrm{KHz}$ to $50 \mathrm{KHz}$ varies from $98.5 \%$ to $93.2 \%$ while the $\mathrm{SiC}$ device Cree (404A) varies $99.8 \%$ to $98.9 \%$ for the same frequency level above results show various $\mathrm{SiC}$ devices efficiency's which are of minimum extent

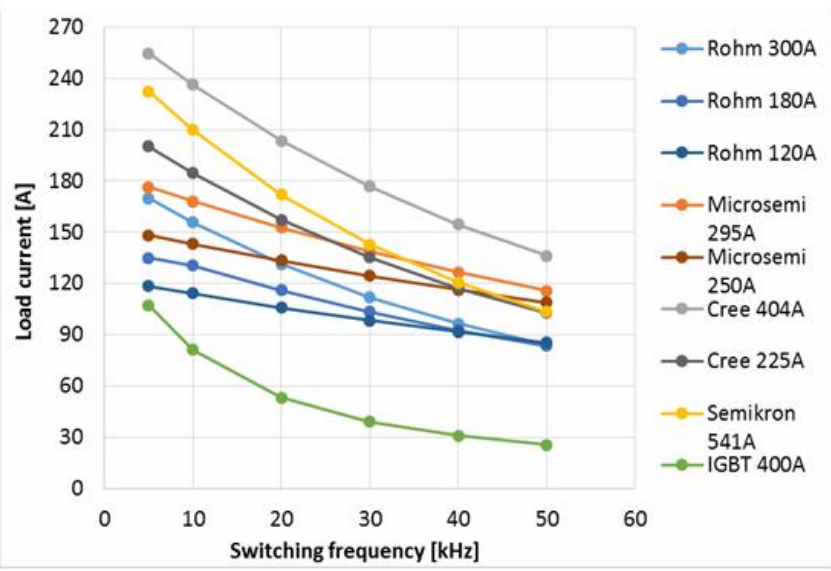

Fig 4: Fixed Power Losses -Maximum Switching Frequency

From Figure 4 it is observed that the load current for IGBT(400A) Si Device from $5 \mathrm{KHz}$ to $50 \mathrm{KHz}$ varies from 110A t 30A while the $\mathrm{SiC}$ device Cree (404A) varies from 250Ato 140Afor the same frequency level above results show various $\mathrm{SiC}$ devices load current varies which are of minimum extent.

\section{RESULT \& SIC (BSM30012P2E001) AND SI (K2611) POWER MODULE PERFORMANCE IN DC/DC BUCK CONVERTER:}

In this paper the performance of bidirectional buck converter switching devices is replaced with N-Channel Si MOSFET (K6211) and silicon carbide device (BSM30012P2E001).

On placing the properties of these two devices it is observed that $\mathrm{SiC}$ switching devices shows better performance than $\mathrm{Si}$ Mosfet. The output voltage is well tracked in the $\mathrm{SiC}$ device which shows that the converter efficiency is improved.

\section{A: Si (K2611):}

This N-Channel Si MOSFET enhanced mode power field effect transistors are produced using Winsemi's proprietary, plane stripe and DMOS technology. This is used in switch performances and withstands more energy pulse in the avalanche and commutation. These devices are best suited for switching mode power supplies.
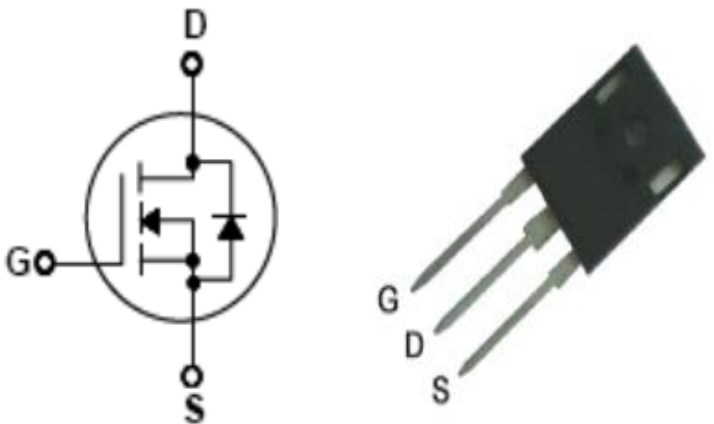

Fig 5: Symbol of N -Channel Si MOSFET

The electrical parameters of K2611 Silicon N channel Mosfet are given in below table

Table 2: Electrical parameters of Si Device

\begin{tabular}{|c|c|c|c|c|}
\hline $\begin{array}{c}\text { S. } \\
\text { no. }\end{array}$ & Parameter & Symbol & Conditions & Value \\
\hline 1 & $\begin{array}{c}\text { Drain source on } \\
\text { state voltage }\end{array}$ & $\mathrm{V}_{\mathrm{ds}}$ & - & $900 \mathrm{~V}$ \\
\hline 2 & $\begin{array}{c}\text { Drain cut-off } \\
\text { current }\end{array}$ & $\mathrm{I}_{\mathrm{dss}}$ & & $11 \mathrm{~A}$ \\
\hline 3 & $\begin{array}{c}\text { Gate source } \\
\text { voltage }\end{array}$ & $\mathrm{V}_{\mathrm{gs}}$ & $\begin{array}{c}\mathrm{V}_{\mathrm{ds}}=5 \mathrm{~V}, \mathrm{I}_{\mathrm{d}} \\
=250 \mu \mathrm{A}\end{array}$ & $+/-30 \mathrm{~V}$ \\
\hline 4 & $\begin{array}{c}\text { Gate source } \\
\text { leakage current }\end{array}$ & $\mathrm{I}_{\mathrm{gss}}$ & $\begin{array}{c}\mathrm{V}_{\mathrm{gs}}=-30 \text { to } \\
30 \mathrm{~V}\end{array}$ & -100 to \\
& & $\mathrm{t}_{\mathrm{don}}$ & $\mathrm{I}_{\mathrm{d}}=11 \mathrm{~A}$, & $100 \mathrm{nA}$ \\
\cline { 3 - 5 } 5 & $\begin{array}{c}\text { Switching } \\
\text { Characteristics }\end{array}$ & $\mathrm{t}_{\mathrm{r}}$ & $\mathrm{V}_{\mathrm{ds}}=458 \mathrm{~V}$ & $280 \mathrm{~ns}$ \\
\cline { 3 - 5 } & & $\mathrm{t}_{\mathrm{rr}}$ & $\mathrm{I}_{\mathrm{d}}=300 \mathrm{~A}$ & $50 \mathrm{~ns}$ \\
\cline { 3 - 5 } & & $\mathrm{t}_{\mathrm{f}}$ & $\mathrm{R}_{\mathrm{g}}=25 \Omega$ & $340 \mathrm{~ns}$ \\
\hline 6 & \multirow{2}{*}{$\begin{array}{l}\text { Input } \\
\text { Capactive }\end{array}$} & $190 \mathrm{~ns}$ \\
\hline 7 & \multirow{2}{*}{$\begin{array}{l}\text { Stray } \\
\text { inductance }\end{array}$} & $\mathrm{C}_{\mathrm{iss}}$ & & $3500 \mathrm{pf}$ \\
\hline
\end{tabular}
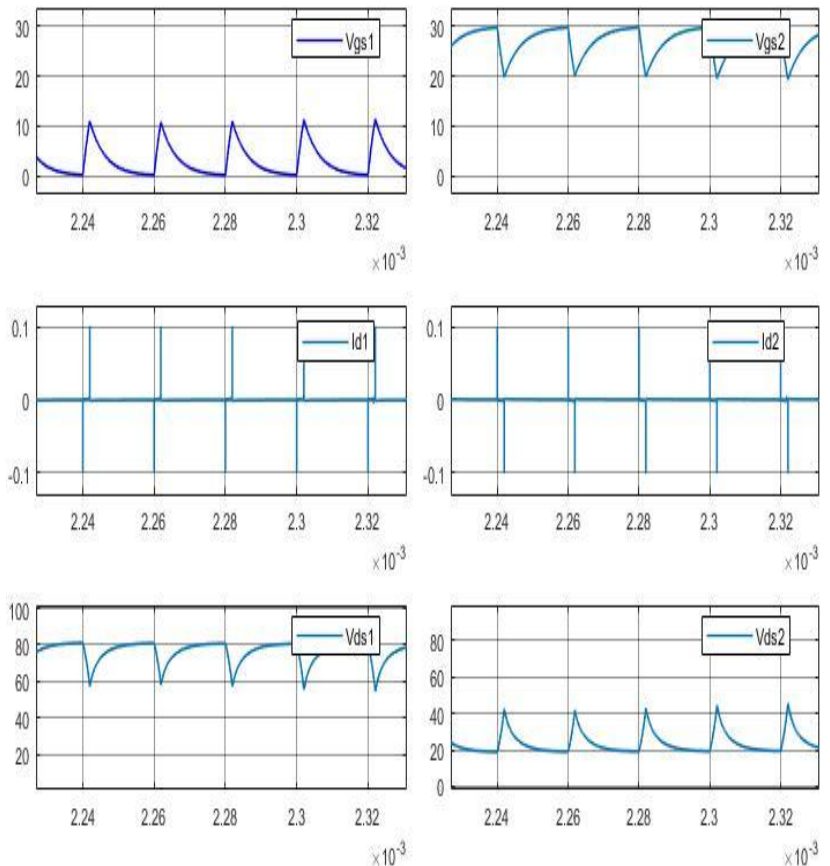

Fig 6: Performance characteristics of bidirectional buck converter using (k6211) Mosfet 
Figure 6 consists of the gate source voltages of the two switches and diode currents and drain source voltages. It is observed that the two switches are in opposite conducting mode and at an interval of $2 \mathrm{~ms}$ at $10 \mathrm{~V}$ amplitude for $\mathrm{Vgs}$, and $20 \mathrm{~V}$ amplitude for Vds.

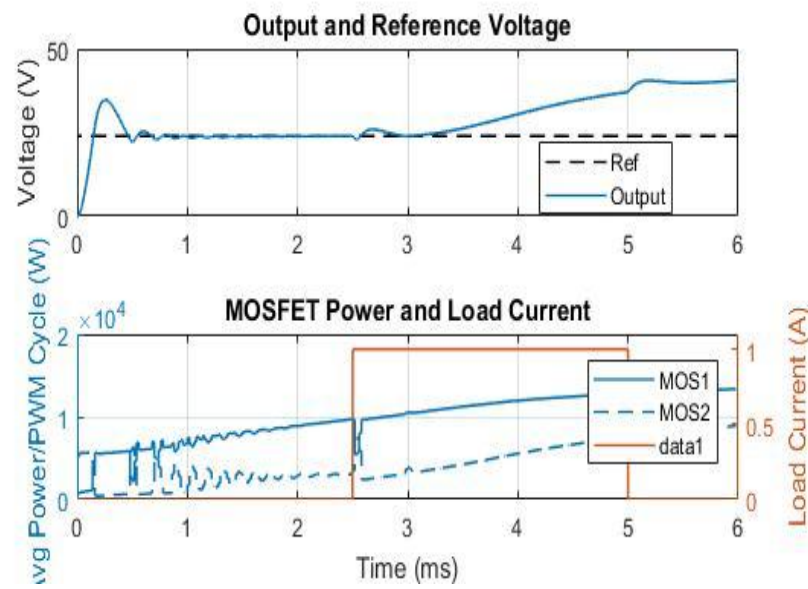

Fig 7: Output voltage curve and Average Power for bidirectional buck converter using (k6211) Mosfet

Figure 7 consists of the output Voltage and average power for a bidirectional converter. It is observed that the output voltage is tracked with the reference voltage and at around $3.2 \mathrm{~ms}$ it is deviated .The average power of the two mosfet switches is being observed with constant cyclic load current that occurs at $2.5 \mathrm{~ms}$ to $5 \mathrm{~ms}$.

\section{B: Si C (BSM30012P2E001):}

The applications of $\mathrm{SiC}$ power module BSM30012P2E001 are motor drive, inverter, converters, photovoltaic's, wind power generation, induction heating equipment. This product is a combination of half bridge consisting of SiC- DMosfet and SiC-SBD (Scokty Barrier Diode). The advanced technology has been especially tailored to minimize on-state resistance and are used for high efficiency.

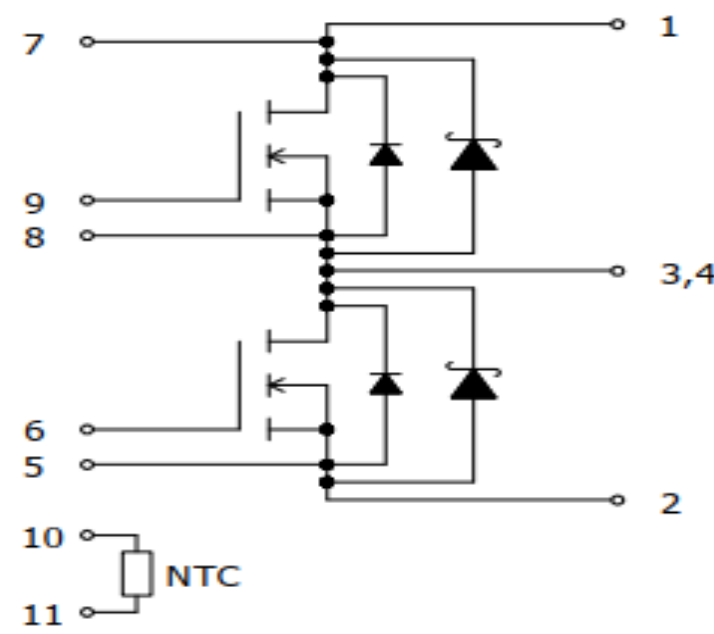

Fig 8: Symbol of Rohm 300A SiC device

The electrical parameters of BSM30012P2E001 are given in below table. The desirable features are it has low surge, low switching losses, high speed switching capability and reduced temperature dependent. It has low leakage currents and operates at high desirable temperature.

Table 3: Electrical parameters of $\mathrm{SiC}$ (BSM30012P2E001) Device

\begin{tabular}{|c|c|c|c|c|}
\hline Sno & Parameter & Symbol & Conditions & Value \\
\hline 1 & $\begin{array}{l}\text { Static drain source } \\
\text { on state voltage }\end{array}$ & $\mathrm{V}_{\mathrm{ds}}($ on $)$ & $\begin{array}{c}\mathrm{I}_{\mathrm{d}}=300 \mathrm{~A} \\
\mathrm{~V}_{\mathrm{gs}}=18 \mathrm{~V}\end{array}$ & $\begin{array}{l}2.2 \mathrm{~V}- \\
2.9 \mathrm{~V}\end{array}$ \\
\hline 2 & $\begin{array}{l}\text { Drain cut-off } \\
\text { current }\end{array}$ & $\mathrm{I}_{\mathrm{dss}}$ & $\begin{aligned} \mathrm{V}_{\mathrm{ds}}= & 1200 \mathrm{~V}, \mathrm{~V}_{\mathrm{gs}} \\
& =0 \mathrm{~V}\end{aligned}$ & $3.2 \mathrm{~mA}$ \\
\hline 3 & $\begin{array}{l}\text { Gate source } \\
\text { threshold voltage }\end{array}$ & $\mathrm{V}_{\mathrm{gs}}$ & $\begin{array}{c}\mathrm{V}_{\mathrm{ds}}=10 \mathrm{~V}, \mathrm{I}_{\mathrm{d}} \\
=68 \mathrm{~mA}\end{array}$ & $1.6-4 \mathrm{~V}$ \\
\hline 4 & $\begin{array}{l}\text { Gate source leakage } \\
\text { current }\end{array}$ & $\mathrm{I}_{\mathrm{gss}}$ & $\mathrm{V}_{\mathrm{gs}}=-6$ to $22 \mathrm{~V}$ & $\begin{array}{l}-0.5 \text { to } \\
0.5 \mu \mathrm{A}\end{array}$ \\
\hline \multirow{5}{*}{5} & \multirow{5}{*}{$\begin{array}{l}\text { Switching } \\
\text { Characteristics }\end{array}$} & $t_{\text {don }}$ & $\begin{array}{l}\mathrm{V}_{\mathrm{gson}}=18 \mathrm{~V}, \\
\mathrm{~V}_{\mathrm{gsoff}}=0 \mathrm{~V}\end{array}$ & $80 \mathrm{~ns}$ \\
\hline & & $\mathrm{t}_{\mathrm{r}}$ & $\mathrm{V}_{\mathrm{ds}}=600 \mathrm{~V}$ & $70 \mathrm{~ns}$ \\
\hline & & $\mathrm{t}_{\mathrm{rr}}$ & $\mathrm{I}_{\mathrm{d}}=300 \mathrm{~A}$ & $50 \mathrm{~ns}$ \\
\hline & & $t_{\text {doff }}$ & $\mathrm{R}_{\mathrm{g}}=0.2 \Omega$ & $250 \mathrm{~ns}$ \\
\hline & & $t_{f}$ & Inductive load & $65 \mathrm{~ns}$ \\
\hline 6 & Input Capacitance & $\mathrm{C}_{\text {iss }}$ & & $32 \mathrm{nf}$ \\
\hline 7 & Gate resistance & $\mathrm{R}_{\text {gint }}$ & & $1.6 \Omega$ \\
\hline 8 & Stray inductance & $\mathrm{L}_{\mathrm{s}}$ & & $13 \mathrm{nH}$ \\
\hline
\end{tabular}

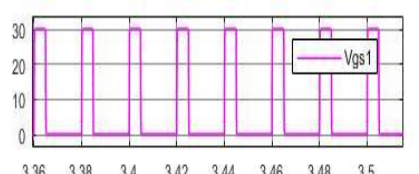

$\begin{array}{llllllll}3.36 & 3.38 & 3.4 & 3.42 & 3.44 & 3.46 & 3.48 & 3.5\end{array}$

$\times 10^{-3}$
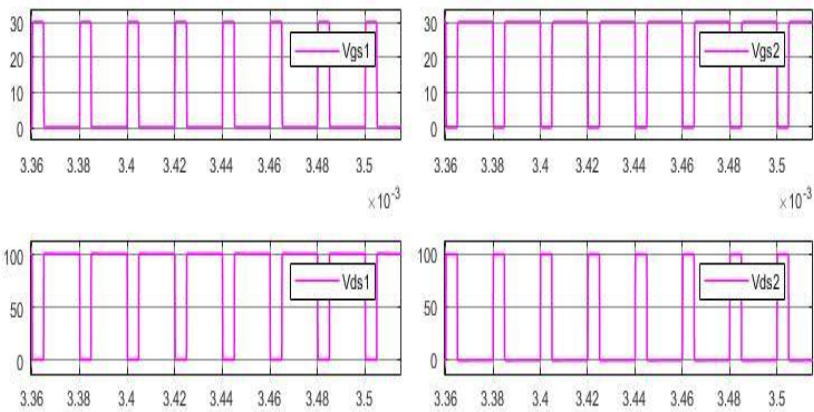

$\times 10^{-3}$
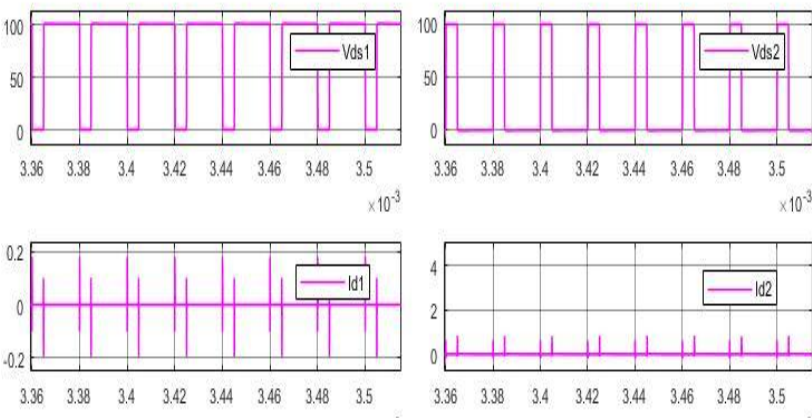

$\times 10^{3}$

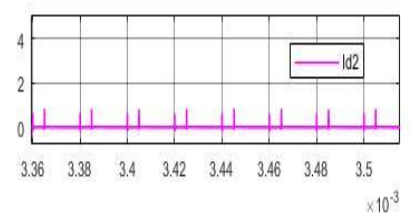

Fig 9: Performance characteristics of bidirectional buck converter using (BSM30012P2E001) SiC-DMosfet and SiC SBD

Figure 9 consists of the gate source voltages of the two switches and diode currents and drain source voltages. It is observed that the two switches are in opposite conducting mode and at an interval of $2 \mathrm{~ms}$ at $30 \mathrm{~V}$ amplitude for $\mathrm{Vgs}$ and $100 \mathrm{~V}$ amplitude for $\mathrm{Vds}$.
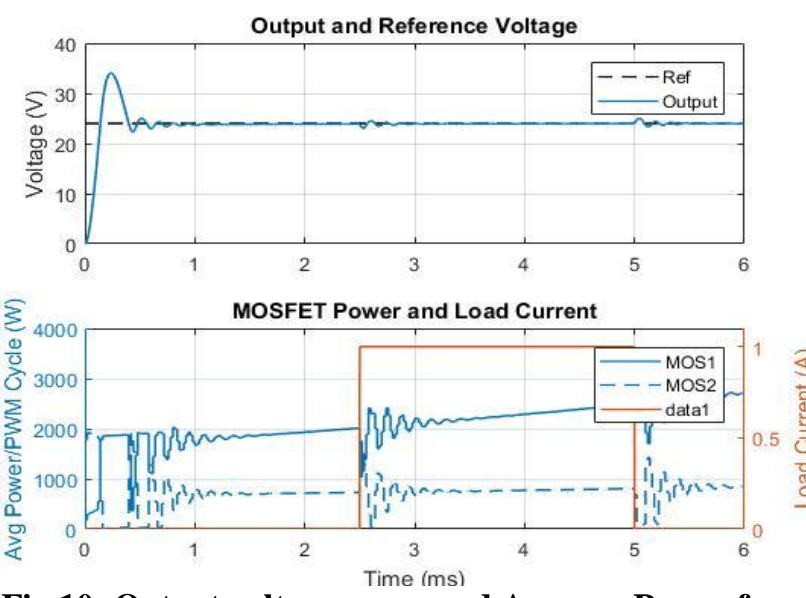

Fig 10: Output voltage curve and Average Power for bidirectional buck converter using (BSM30012P2E001) SiC-DMosfet and SiC SBD 
Figure 10 consists of the output Voltage and average power for a bidirectional converter. It is observed that the output voltage is well tracked with the reference voltage. The average power of the two mosfet switches is being observed with constant cyclic load current that occurs at $2.5 \mathrm{~ms}$ to $5 \mathrm{~ms}$.
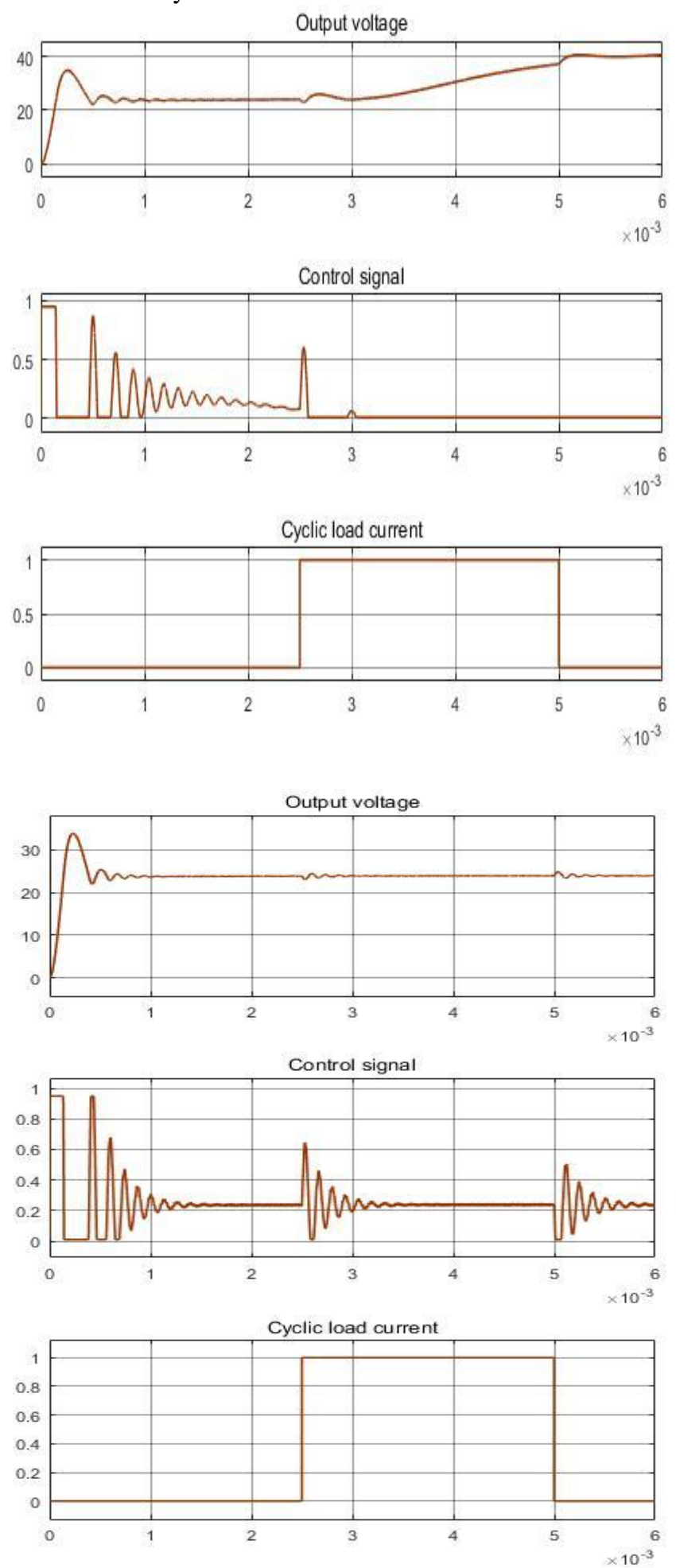

Fig 11: Comparison of output voltage for $\mathrm{Si}$ and $\mathrm{SiC}$ at constant load current

In Figure 11 at constant cyclic load current that occurs at $2.5 \mathrm{~ms}$ to $5 \mathrm{~ms}$ the output voltage observed in $\mathrm{Si}$ mosfet deviates the reference voltage but the $\mathrm{SiC}$ device is well tracked with reference voltage. From this fig the $\mathrm{SiC}$ devices are useful for fast switching and are superior in performance rather than Si device.
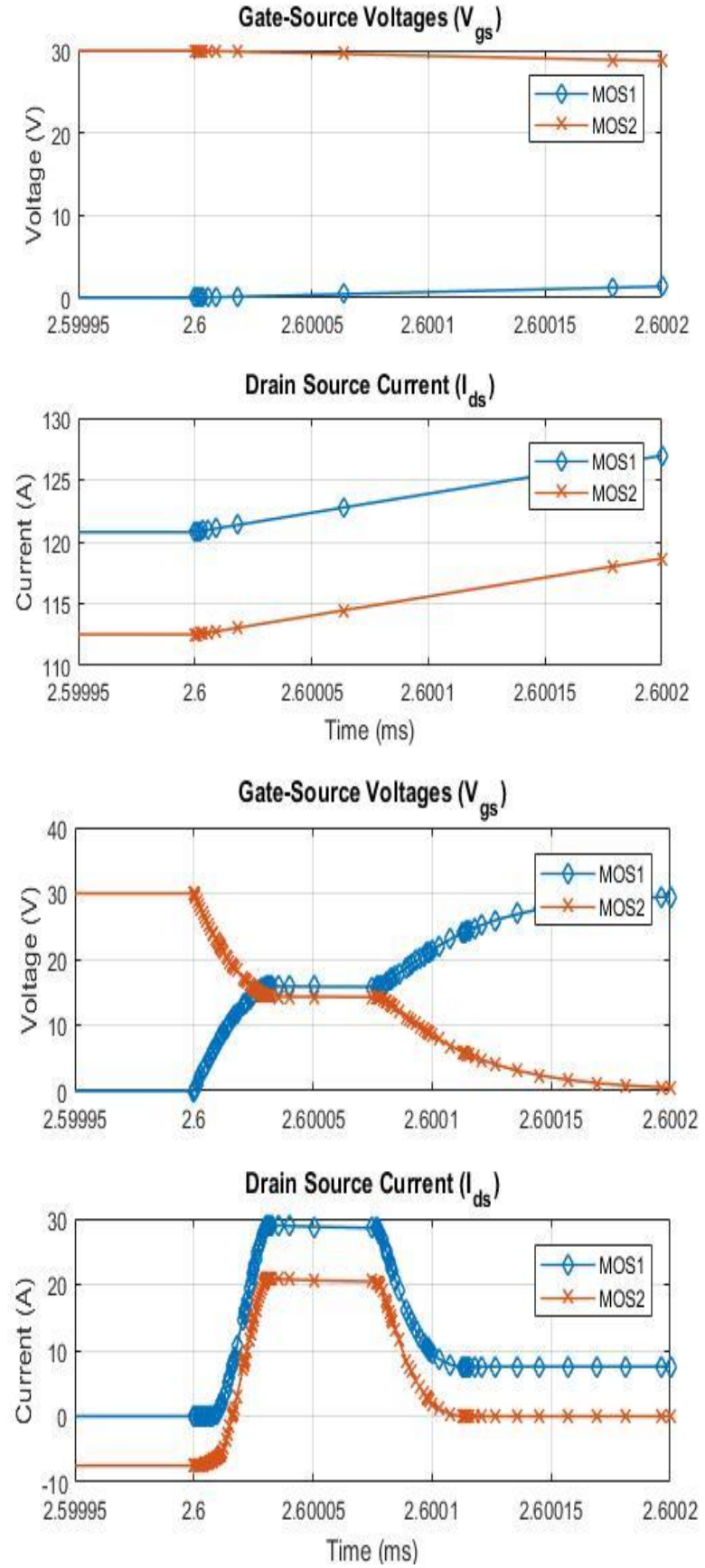

Fig 10: Output voltage curve and Average Power for bidirectional buck converter using (BSM30012P2E001) SiC-DMosfet and SiC SBD

Figure 10 consists of the output Voltage and average power for a bidirectional converter. It is observed that the output voltage is well tracked with the reference voltage .The average power of the two mosfet switches is being observed with constant cyclic load current that occurs at $2.5 \mathrm{~ms}$ to $5 \mathrm{~ms}$.

\section{CONCLUSION}

The progress of silicon carbide devices in recent trends is briefly discussed and a comparison of loss modelling of these devices is analyzed. The performance efficiency of these devices are superior than silicon mosfet. SiC devices withstand at high operating temperatures and produce high power, 
high frequency and high voltage. Furthermore the comparative performance characteristics show that the silicon carbide device BSM30012P2E001a combination SiC-DMosfet and SiC SBD shows superior characteristics than N -Channel Si MOSFET k2611.

\section{REFERENCES}

1 High-Frequency PWM Buck Converters Using GaN-on-SiC HEMTs, IEEE transactions on power electronics', VOL. 29, NO. 5, May 2014 work done by Miguel Rodrguez Yuanzhe Zhang, Dragan Maksimovic,

2. K.V.R.Swathi \& U.Salma "Characterization of SIC in Buck and Design of Buck with Coupled Inductor for High Efficiency in Robotic Applications"Jour of Adv Research in Dynamical \& Control Systems, Vol. 10, 10-Special Issue, 2018

3. "A PWM plus phase shift control bidirectional DC-DC converter," IEEE Transactions on Power Electronics, 19(3), 2008 D. Xu, C. Zhao, \& H. Fan

4. Control of interleaved synchronous PWM buck converters, Control and Intelligent Systems, 36(4),2008 by H.E. Fadil \& F. Giri, Robust

5. High efficiency buck led driver using $\mathrm{SiC}, 1$ st international conference on power engineering ,computing and control, Science Direct Energy procedia 1 17(2017) Pg 224-235 by R.Srimathi, S.Sitoke, S.hemamalini,

6. Rohm Semiconductors, SiC Power Devices and Modules, Application note, Issued in August 2014, 14103EBY01.

7. Hangseok Choi, Overview of Silicon Carbide Power Devices, Fair child Semi conductor industry.

8. L. Ravi, E. Severson, S. Tewari, N. Mohan, "Circuit-level characterization and loss modeling of SiC-based power electronic converters," in Industrial Electronics Conference (IECON), 2014 IEEE, Oct 2014

9. M. Briere, "The power electronics market and the status of $\mathrm{GaN}$ based power devices," in Compound Semiconductor Integrated Circuit Symposium (CSICS), 2011 IEEE, Oct 2011, pp. 1-4.

\section{AUTHORS PROFILE}

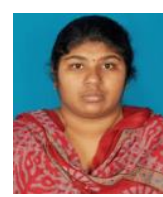

K.V.R.Swathi, was born on $1^{\text {st }}$ December 1983 in Visakhapatnam. She received her B.Edegree in Electrical and Electronics Engineering from ANITS affiliated to Andhra University Visakhapatnam, India in 2005. She received her M.E degree in Power electronic drives and Control, Andhra University Visakhapatnam, India in 2012. Currently she is working as an Assistant Professor in the department of Electrical and Electronics Engineering, Anil Neerukonda Institute of technology and sciences Andhra University, Visakhapatnam, AP, India. Her research interests include converter topologies, soft computing techniques, control methods, machine modeling.

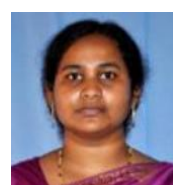

Dr. U. Salma,was born on $30^{\text {th }}$ August 1980 in Kakinada .Shecompleted her Bachelors and Masters degrees in Electrical and Electronics Engineering from JNT University Hyderabad, India in 2002 and 2006 respectively. She received her $\mathrm{Ph}$. D degree in Electrical and Electronics Engineering in JNT University, Kakinada, India in 2016. Currently she is working as an Associate Professor in the department of Electrical Electronics and Communication Engineering, GITAM Institute of Technology, GITAM University, Visakhapatnam, AP, India. Her research interests include reduced order modeling, soft computing techniques, optimization techniques, power system stability. 